\title{
Genomic analysis of serologically untypable human enteroviruses in Taiwan
}

\author{
Yeh-Sheng Chien ${ }^{1,2}$, Shu-Ting Luo' ${ }^{1}$ Kuo-Chien Tsao ${ }^{3,4}$, Yhu-Chering Huang ${ }^{4}$, Wan-Yu Chung ${ }^{1}$, Yu-Chieh Liao ${ }^{6}$,
} Yi $\operatorname{Tan}^{5}$, Suman R. Das ${ }^{5}$ and Min-Shi Lee ${ }^{1,7^{*}}$ (D)

\begin{abstract}
Background: Human enteroviruses contain over 100 serotypes. We have routinely conducted enterovirus surveillance in northern Taiwan; but about $10 \%$ of isolates could not be serotyped using traditional assays. Next-generation sequencing (NGS) is a powerful tool for genome sequencing.

Methods: In this study, we established an NGS platform to conduct genome sequencing for the serologically untypable enterovirus isolates.

Results: Among 130 serologically untypable isolates, 121 (93\%) of them were classified into 29 serotypes using CODEHOP (COnsensus-DEgenerate Hybrid Oligonucleotide Primer)-based RT-PCR to amplify VP1 genes (VP1-CODEHOP). We further selected 52 samples for NGS and identified 59 genome sequences from 51 samples, including 8 samples containing two virus genomes. We also detected 23 genome variants (nucleotide identity $<90 \%$ compared with genome sequences in the public domain) which were potential genetic recombination, including 9 inter-serotype recombinants and 14 strains with unknown sources of recombination.
\end{abstract}

Conclusions: We successfully integrated VP1-CODEHOP and NGS techniques to conduct genomic analysis of serologically untypable enteroviruses.

Keywords: Enterovirus, Virus surveillance, Molecular epidemiology, Next-generation sequencing

\section{Background}

Enteroviruses (EV) are single-stranded, positive-sense RNA viruses in the Enterovirus genus of the Picornaviridae family. All enteroviruses have a similar genomic organization $(7.2-8.5 \mathrm{~kb})$. The capsid proteins are coded on the 5 'end of the ssRNA in a section called P1 (precursor 1). The nonstructural proteins are coded on the remaining sections of the genome, which are called P2 and P3. Changes in the structural protein genes of different enterovirus species reflect phylogenetic relationships. EV cause various clinical manifestations, including cutaneous, visceral, and neurological diseases. The Enterovirus genus consists of 12 species, including Enterovirus A (EV-A, 25 serotypes), Enterovirus B (EV-B, 63 serotypes), Enterovirus C (EV-C,

\footnotetext{
* Correspondence: minshi.lee@hotmail.com

${ }^{1}$ Institute of Infectious Disease and Vaccinology, National Health Research Institutes, Zhunan, Miaoli County, Taiwan

${ }^{7}$ National Health Research Institutes, R1-7F, 35 Keyan Road, Zhunan, Miaoli County 350, Taiwan

Full list of author information is available at the end of the article
}

23 serotypes), Enterovirus D (EV-D, 5 serotypes), Enterovirus $E$ (EV-E, 4 serotypes), Enterovirus F (EV-F, 6 serotypes), Enterovirus G (EV-G, 11 serotypes), Enterovirus $\mathrm{H}$ (EV-H, 1 serotype), Enterovirus J (EV-J, 6 serotypes), Rhinovirus A (80 serotypes), Rhinovirus B (32 serotypes), and Rhinovirus C (55 serotypes) [44]. The first 4 species belong to human EV, which usually cause self-limited infections except polioviruses, EV-A71, EV-D68, and some echoviruses and coxsackieviruses [32, 38, 39]. Polioviruses have been the most important EVs for many years because they caused large outbreaks of paralytic disease before poliovirus vaccines were available.

Based on enterovirus surveillance in a medical center in northern Taiwan, there are about $10-20 \%$ of enteroviruses could not be serotyped using available monoclonal antibodies annually [41]. Those untypable enteroviruses were positive for the pan-enterovirus blend antibody but negative for all other immunofluorescent assay (IFA) antibodies, which are likely to be new serotypes or novel 
enteroviruses with gene mutations or recombinations [41]. Frequent recombinations and mutations in enteroviruses, which have been recognized as the main mechanisms for the observed high rate of evolution, enable EV to rapidly respond and adapt to new environmental challenges. Therefore, it is desirable to characterize these serologically untypable enteroviruses using novel molecular techniques.

The U.S. Centers for Disease Control and Prevention (CDC) has developed a primer design strategy for PCR amplification of distantly related VP1 gene sequences based on consensus-degenerate hybrid oligonucleotide primers (VP1-CODEHOP) [31]. We have employed the VP1-CODEHOP method to identify enterovirus serotypes using clinical specimens (throat swabs) [41]. Although the CODEHOP method is widely used for enterovirus typing in research labs [5, 20,34], it is still not a routine method for enterovirus surveillance in public health labs [14]. In 2015, the World Health Organization recommend the CODEHOP method for poliovirus surveillance [1]. Recently, next-generation sequencing (NGS) technology has been applied to conduct virus genomic studies and identify novel enteroviruses [10, 33]. In this study, we first identified serologically untypable enterovirus strains through the VP1-CODEHOP method. Then enterovirus RNA were extracted for NGS to obtain the full genome sequences of enteroviruses. The enterovirus genome data were further used to identify novel enteroviruses and conduct molecular epidemiological analysis, which are critical for enterovirus surveillance and vaccine development.

\section{Methods}

Viruses

Chang Gung Memorial Hospital is a medical center in northern Taiwan that routinely receives clinical specimens for virus culture. The clinical specimens include respiratory (throat swabs and nasopharyngeal aspirates) and other specimens, including blood, cerebral spinal fluid, and rectal swabs. Cell culture and virus isolation were conducted according to the protocols employed commonly in clinical virology laboratories, and clinical isolates were further serotyped by immunofluorescent assay (IFA) using pan-enterovirus antibody and typespecific antibodies [41]. We obtained 130 IFA-untypable clinical isolates from Linkou Chang Gung Memorial Hospital. Human rhabdomyosarcoma (RD) cells and human lung (MRC-5) cells were used to grow enteroviruses following the standard procedures [30].

\section{CODEHOP method}

Viral RNA was extracted using a QIAamp Mini Viral RNA Extraction Kit (Qiagen, Germany). EV VP1 gene (350 to $400 \mathrm{bp}$ ) was amplified as described in detail previously [31, 32]. The amplified DNA was sequenced using the ABI
3730 XL DNA Analyzer (Applied Biosystems, Foster City, CA). Nucleotide sequences of the partial VP1 gene were analyzed using the BLAST search in the GenBank database to find the enterovirus serotype with the highest identity. Alignment of the nucleotide sequences and phylogenetic analysis were conducted as described in detail previously $[31,32]$.

\section{Virus purification and concentration}

The NGS technique is powerful tool for viral genome sequencing, but interference of host-cell nucleotides needs to be overcome $[3,15,22]$. To remove host-cell nucleotides, we identify a protocol to purify viruses RNA (Additional file 3). First, virus supernatant $(2 \mathrm{ml})$ was treated with $0.05 \%$ formalin for $8 \mathrm{~h}$ for inactivation. The treated virus supernatant was filtered with $0.22 \mu \mathrm{m}$ filter to remove cell debris. Then, virus particles were purified and concentrated using sucrose gradient ultracentrifugation. The filtered virus supernatant $(1.5 \mathrm{~mL})$ was loaded onto three layer of continuous sucrose buffer (PBS, 20,30\%) and centrifuged at $36,000 \mathrm{rpm}$ for six hours using a Beckman SW 41-Ti rotor. We collected the virus pellet in $50 \mu \mathrm{l} \mathrm{PBS}$ buffer. Enteroviruses RNA were extracted after the ultracentrifugation process.

After preparing the enterovirus RNA samples, we analyzed the quality of virus RNA to eliminate contamination of ribosomal RNA. We detected the $\mathrm{Cp}$ value of $18 \mathrm{~s}$ ribosomal RNA and enterovirus RNA by real-time PCR (Additional file 1).

\section{Real-time PCR reaction and primers design}

Enteroviruses RNA were quantified using qRT-PCR. Purified Virus RNA extraction and first strand cDNA synthesis were conducted following standard procedures [5]. EV71 viral RNA was assessed by qRT-PCR analysis with the Applied Biosystems (Thermo Fisher Scientific) RealTime PCR system and the EV71 5'UTR primer pair. The highly conserved 5'UTR gene of the enteroviruses was chosen as the target for the synthesis of a 140-bp cDNA with primers EV509-EVF1 (5'-CCC TGA ATG CGG CTA ATC CT-3'), EV510-EVF1 (5'-CCT GAA TGC GGC TAA TCC YA-3'), and EV-R1 (5'-ATTGTCACCATAAGCAGYCR-3').

\section{Next-generation sequencing (NGS)}

In the pilot NGS study, we used the Illumina sequencing technology at National Yang-Ming University's Research Center (Miseq, $2 \times 250$ bp reads, $40 \mathrm{M}$ total reads).In NGS study two, 51 enteroviruses complete genomes were sequenced at the J. Craig Venter Institute. Illumina libraries were prepared using the Nextera DNA sample preparation kit (Illumina, San Diego, CA, USA) with half-reaction mixture volumes as described previously [39]. In order to characterize all enteroviruses serotypes, 
we used random primers in this study. All sequences were de novo assembled using CLC bio's clc_ novo_assemble program (CLC Genomics Workbench 4.6.1).

\section{Recombination detection and phylogenetic analysis}

All sequence alignments were constructed using the Muscle algorithms of the MEGA program version 4.0 (Arizona State University, AZ, USA). Potential recombinants with 1140 complete genome sequences of enteroviruses (Additional file 6) were screened using seven methods (RDP, GENECONV, MaxChi, Bootscan, Chimaera, SiScan, and 3Seq) implemented in the Recombination Detection Program version 4.46 (RDP4) [26]. The recombination events were then confirmed by constructing a phylogenetic dendrogram using the MEGA program version 4.0.

\section{Data access}

All sequences have been submitted to the GenBank; the accession numbers are KT318494, KT353719KT353725, and MF422531-MF422581.

\section{Results}

Characterization of IFA-untypable enteroviruses using the VP1-CODEHOP method

We collected 130 enterovirus isolates that could not be serotyped by IFA. Among these 130 samples, 121 were successfully identified as 19 different serotypes using the VP1-CODEHOP. The remaining 9 samples could not be identified using the VP1-CODEHOP and they were further amplified in cell cultures for genome sequencing using NGS (Fig. 1).

\section{Identification of untypable enterovirus by NGS}

To further characterize the nine samples that could not be identified using the VP1-CODEHOP method, we first amplified these enterovirus isolates in RD and MRC-5 cells. Of these nine samples, two developed massive cytopathic effects (CPE), six developed low CPE, and one had no CPE (Fig. 1). Based on qPCR targeting virus 5'UTR, Ct for these three groups were 15-23, 34-35, and 37, respectively, which indicates that the samples without CPE had very low virus RNA concentrations and would not be suitable for NGS sequencing. In an NGS pilot study, we selected 13 samples for genome sequencing, including 2 samples with massive CPE, 3 samples with low CPE, 6 samples identified in the VP1-CODEHOP, and 2 positive control samples (EV-A71 and CV-A2) that have been sequenced with the Sanger method (Fig. 1). The distribution of read numbers for each enterovirus genome was 20,201 to 123,641 reads, and the average read number was about 80,476 reads (Additional file 5).

As shown in Additional file 1, we obtained 10 genome sequences from the untypable samples; and one sample (1-C2) with low CPE failed. Based on sequence alignments of the positive control samples (EV-A71 and CVA2), identity between NGS and Sanger sequencing was 99.6\% (7376/7402) and 99.9\% (7306/7309), respectively.

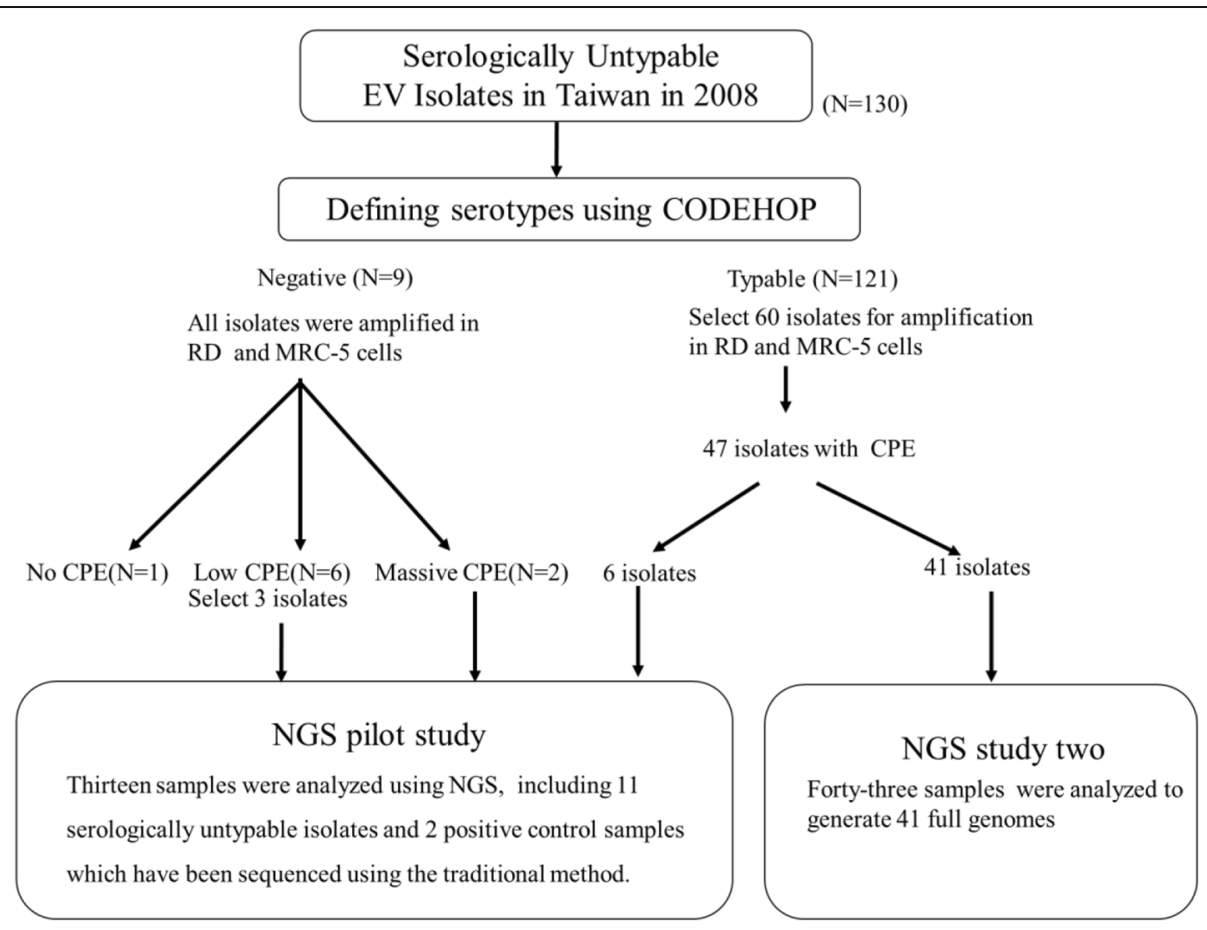

Fig. 1 Flowchart of enterovirus genomic study 
Four samples (sample ID 2-D5, 2-E6, 2-B2, and 2-B9) could not be identified using the VP1-CODEHOP, and they were sequenced as echovirus 6 , echovirus 3 , rhinovirus A39, and parechovirus 1 using NGS. Among the 6 samples that could be identified using the VP1CODEHOP, all of them could also be identified and sequenced using NGS. Based on the success of the NGS pilot study, we further employed NGS to analyze other 41 samples that could be typed using the VP1CODEHOP. Some samples were selected for NGS because their serotypes have few genome sequences available in the public domain, such as CV-A2, CV-A4, CVA5, CV-A9, Echo 3, Echo 6, Echo 9, Echo 25, Echo 30, and rhinovirus A39 (Fig. 1 and Table 1). Among these 41 samples, 49 enterovirus genome sequences were obtained, including 8 samples with two virus genomes. Overall, we obtained 59 genome sequences from 51 cases for further analysis (Table 1). Serotypes of the genome sequences were determined by BLAST and phylogenetic analysis (Fig. 2). Demographics and clinical presentations of these 51 cases are listed in Additional file 2.

\section{Recombination detection}

Based on phylogenetic analysis, serotypes of the 59 genomes could be classified into 17 enterovirus serotypes (Fig. 2). There is no official definition of genome variants. To identify recombinant viruses, we selected genome variant of $90 \%$ identity as screening standards. Among them,
23 genomes had low genetic identity $(<90 \%)$ compared with sequence data in the public domain and they are considered as genomic variants which may be derived from genetic recombination. These 23 genomes were classified into six serotypes (CV-A2, CV-A10, HPeV 1, Echo 3, Echo 6, and Echo 9). Among them, three serotypes (CV-A10, Echo 3, and Echo 9) have two genome groups based on phylogenetic analysis (Fig. 3). Based on analysis using the RDP program, we detected only one potential recombination event. Therefore, we tried to identify recombination events by dividing the 23 genomes into P1, P2, and P3 segments for BLAST analysis (Table 2). Potential breakpoints of the nine genomic groups were further identified using SimPlot (Fig. 4). The $10 \mathrm{CV}$-A2 variants clustered together (Fig. 3), but their recombination events could not be identified (Table 2) (Fig. 4a). Based on BLAST analysis of the VP1 genes, the CV-A2 variants are closest to the CV-A2 viruses isolated in Japan in 2003 (Table 2), which is consistent with phylogenetic analysis of the VP1 genes (data not shown). All CV-A2 cases were mild infections without neurological complications (Additional file 2).

The two CV-A10 variants could be classified into two genomic groups (Fig. 3). The first $\mathrm{CV}$-A10 variant (strain MF422531) is likely a triple recombinant of CV-A10, CVA2, and CV-A6 (Fig. 4b); and the recombination event of the second $\mathrm{CV}-\mathrm{A} 10$ variant could not be identified (Fig. 4c). The two CV-A10 cases were mild infections. The

Table 1 Genomic characterization of serologically-untypable enteroviruses in northern Taiwan

\begin{tabular}{|c|c|c|c|c|c|}
\hline $\begin{array}{l}\text { Serotype by } \\
\text { CODEHOP or NGS }\end{array}$ & $\begin{array}{l}\text { Availability of IFA } \\
\text { antibody }\end{array}$ & $\begin{array}{l}\text { No. of isolates tested } \\
\text { by NGS }\end{array}$ & $\begin{array}{l}\text { No. of full genomes in } \\
\text { public domain }\end{array}$ & $\begin{array}{l}\text { Range of genomic } \\
\text { identity }\end{array}$ & $\begin{array}{l}\text { No. of genomic variants } \\
\text { (identities } \leq 90 \% \text { ) }\end{array}$ \\
\hline CV-A2 & yes & 10 & 14 & $85 \%$ & 10 \\
\hline CV-A4 & yes & 4 & 6 & $97-98 \%$ & 0 \\
\hline CV-A5 & yes & 5 & 6 & $96-97 \%$ & 0 \\
\hline CV-A6 & yes & 5 & 127 & $98 \%$ & 0 \\
\hline CV-A9 & yes & 2 & 25 & 92-99\% & 0 \\
\hline CV-A10 & yes & 2 & 65 & $82-86 \%$ & 2 \\
\hline CV-A16 & yes & 1 & 105 & $99 \%$ & 0 \\
\hline CV-B4 & yes & 6 & 29 & $96-97 \%$ & 0 \\
\hline E3 & no & 7 & 16 & $85-87 \%$ & 7 \\
\hline E6 & yes & 3 & 21 & $88-96 \%$ & 1 \\
\hline E9 & yes & 2 & 12 & 89-90\% & 2 \\
\hline E25 & no & 3 & 7 & $97 \%$ & 0 \\
\hline E30 & yes & 7 & 18 & $97-99 \%$ & 0 \\
\hline PV 1 & no & 1 & 258 & $99 \%$ & 0 \\
\hline EV-D68 & no & 1 & 388 & $97 \%$ & 0 \\
\hline RV-A39* & no & 1 & 3 & $93 \%$ & 0 \\
\hline $\mathrm{HPeV} 1^{*}$ & no & 1 & 38 & $85 \%$ & 1 \\
\hline Total & & 59 & & & 23 \\
\hline
\end{tabular}

"Sample cannot be identified by CODEHOP method 


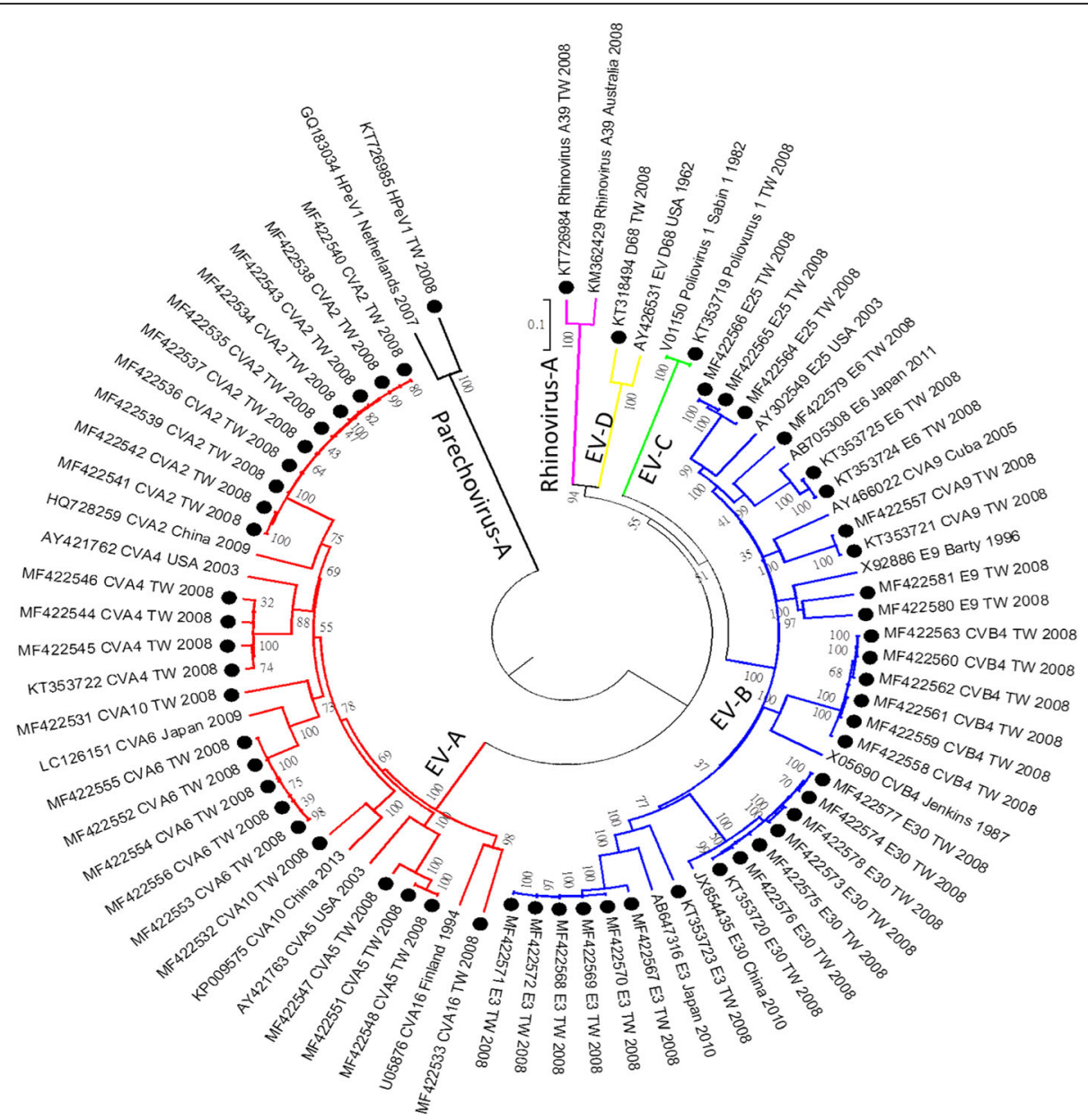

Fig. 2 Phylogenetic analysis of serologically untypable enteroviruses detected in this study and prototype strains based on full genome sequences. The phylogenetic tree was constructed using the neighbor-joining method. Bootstrap values (> 70\%) are shown as percentage derived from 1000 sampling at the nodes of the tree. Red, blue, green, yellow, and purple indicate enterovirus species $\mathbf{a}$, $\mathbf{b}$, c, and $\mathbf{d}$, respectively

seven Echo3 variants could be classified into two groups (Fig. 3). The first Echo3 group has six genomic variants, which are likely recombinants of Echo3 and Echo33 (Fig. $4 \mathrm{~d})$; but the recombination event of the second Echo3 group could not be identified (Fig. 4e). One case in the first genome group develops bacteremia and neurological complications (case 30, Additional file 2). The only Echo6 variant is likely a recombinant of Echo6 and Echo25 (Fig. $4 \mathrm{f})$, and it caused mild infection.

The two Echo9 variants could be classified into two groups (Fig. 3). The first group (MFF422580) is likely a recombinant of Echo9 and Echo6 (Fig. 4g); and the recombination event of the second group (MFF422581) could not be identified (Fig. 4h). Of these two Echo9 cases, the first (MFF422580) causes mild infection while the other (MFF422581) causes meningitis. Interestingly, the RDP program predicted that the Echo9 strain MFF422581 is likely a recombinant of Echo9 Finland 2012 and Echo30 Taiwan 2006 (Additional file 4), but the recombination event could not be confirmed in the BLAST and SimPlot analysis (Table 2) (Fig. 4h). The recombination event of the HPeV1 variant could not be identified (Table 2) (Fig. 4i). Based on BLAST analysis of the VP1 genes, the HPeV1 variant is close to the HPeV1 that circulated in Australia 2010 (Table 2). This HPeV1 causes a mild infection. Overall, 9 of the 23 genomic variants were identified as interserotype recombinants, and recombination events of the other 14 genomic variants could not be identified due to lack of comprehensive genome sequences (Table 2).

\section{Virus co-infection and clinical presentation}

Interestingly, we found eight patients who were coinfected with two enterovirus serotypes (cases 4, 16, 18, $22,23,28,31$, and 32) (Additional file 2) by using NGS. Co-infections could not be easily detected by the CODEHOP method because the dominant serotype will overwhelmingly surpass the minor serotype during the geneamplification process.

Among these eight cases, three developed neurological complications (cases 4, 31, and 32) and one had pneumonia 

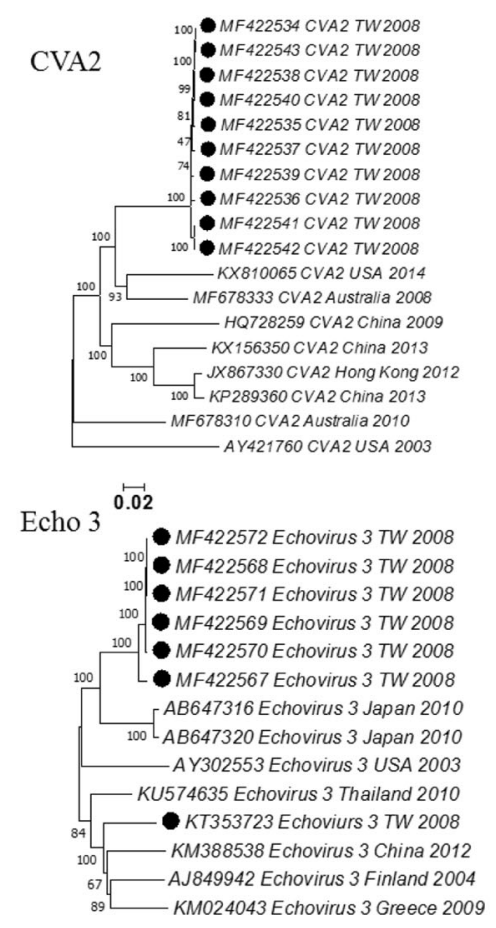

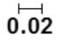

Echo 9

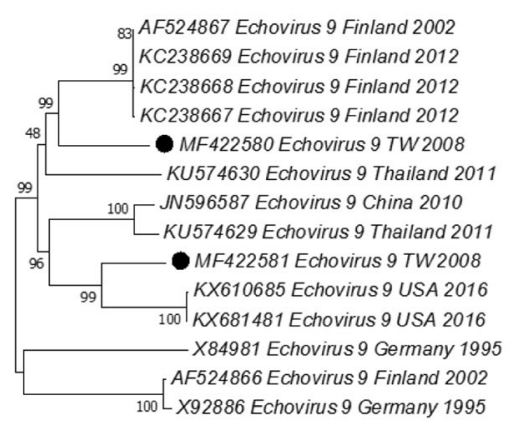

0.02
${ }_{86}$ - KT588920 CVA10 China 2014

$100-$ KP009578 CVA10 China 2013

39 L KP009581 CVA10 2013 China

KJ641623 CVA10 China 2013

Ton 10 o KP289406 CVA10 China 2013

- KX768158 CVA10 China 2015

6. KX768157 CVA10 China 2014

IL KX768168 CVA10 China 2015

L HQ728262 CVA10 China 2009

KX430803 CVA10 VNM 2014

- MF422532 CVA10 TW 2008

$97 \quad$ MF678312 CVA 10 Australia 2007

AY421767 CVA10 USA 2003

0.02

Echo 6

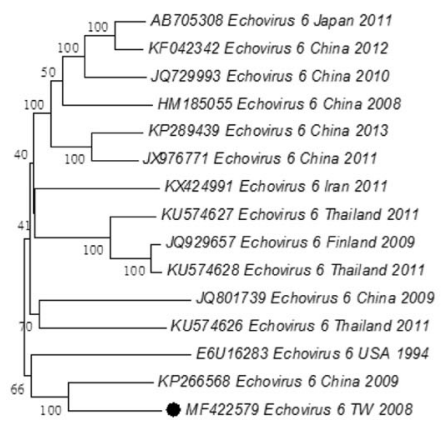

5.02

HPeV 1 100 EF051629 Parechovirus 1 Germany 2007

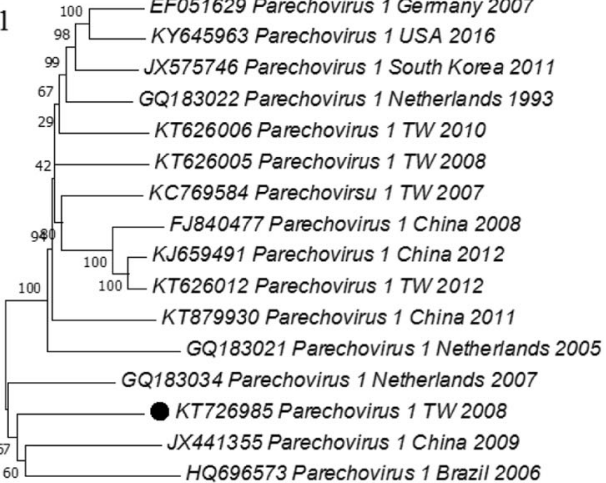

0.02

Fig. 3 Phylogenetic analysis of six enterovirus serotypes with genomic variants detected. Black dot indicates isolates sequenced in this study. The phylogenetic tree was constructed using the neighbor-joining method. Bootstrap values ( $>70 \%)$ are shown as percentage derived from 1000 sampling at the nodes of the tree

(case 23). Among the other 43 cases with a single enterovirus infection, only 4 (cases $33,37,48$, and 49 ) had neurological complications. Overall, enterovirus co-infections were more likely to cause neurological complications than single enterovirus infections ( $p=0.015$, Fisher's Exact Test).

\section{Discussion}

Molecular techniques have gained increasing attention for virus surveillance and the clinical management of infectious diseases. Traditional methods for virus surveillance, including virus isolation and IFA tests, require 5-14 days to complete detection and serotyping. In contrast, the
VP1-CODEHOP test can finish detection and serotyping within $48 \mathrm{~h} \mathrm{[6].} \mathrm{In} \mathrm{the} \mathrm{current} \mathrm{study,} \mathrm{serotypes} \mathrm{of} \mathrm{nine}$ virus samples could not be identified using the VP1CODEHOP. Therefore, we further employed NGS to characterize virus samples that could not be identified using the VP1-CODEHOP. The NGS technique can obtain full genome sequences without the requirement of designing specific primers, but it requires collecting purified virus nucleotide $[3,37,40]$. Therefore, we used sucrose-cushioned ultracentrifugation to purify the virus nucleotide. Among 52 virus samples, only one sample with low CPE could not be sequenced using this platform. 
Table 2 Top sequence identity identified in BLAST analysis of 29 genomic variants

\begin{tabular}{|c|c|c|c|c|c|c|c|c|}
\hline Serotype (No.) & Virus ID & P1 region & Identity & $\mathrm{P} 2$ region & Identity & P3 region & Identity & Break point \\
\hline \multirow[t]{2}{*}{ CVA2 (10) } & $\begin{array}{l}\text { MF422534- } \\
\text { MF422543 }\end{array}$ & $\begin{array}{l}\text { CVA2 Australia } 2010 \\
\text { MF678310 }\end{array}$ & $88 \%$ & $\begin{array}{l}\text { EVA114 India } 2013 \\
\text { KU355876 }\end{array}$ & $87 \%$ & $\begin{array}{l}\text { EVA114 India } 2013 \\
\text { KU355876 }\end{array}$ & $89 \%$ & unknown \\
\hline & & $\begin{array}{l}(\text { CVA2 Japan2003 } \\
\text { AB162722) }\end{array}$ & $(93 \%)^{a}$ & $\begin{array}{l}\text { CVA2 Australia } 2008 \\
\text { MF678333 }\end{array}$ & $86 \%$ & $\begin{array}{l}\text { CVA2 Australia } 2008 \\
\text { MF678333 }\end{array}$ & $88 \%$ & \\
\hline \multirow[t]{4}{*}{ CVA10 (2) } & MF422531 & $\begin{array}{l}\text { CVA10 Australia } 2007 \\
\text { MF678312 }\end{array}$ & $86 \%$ & $\begin{array}{l}\text { CVA2 China } 2013 \\
\text { KX156350 }\end{array}$ & $85 \%$ & $\begin{array}{l}\text { CVA6 TW } 2007 \\
\text { KR706309 }\end{array}$ & $96 \%$ & $P 1-P 2, P 2-P 3$ \\
\hline & & 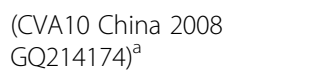 & $(97 \%)^{a}$ & & & & & \\
\hline & MF422532 & $\begin{array}{l}\text { CVA10 China } 2013 \\
\text { KP009581 }\end{array}$ & $85 \%$ & $\begin{array}{l}\text { CVA2 Australia } 2010 \\
\text { MF678310 }\end{array}$ & $86 \%$ & $\begin{array}{l}\text { CVA2 Australia } 2010 \\
\text { MF678310 }\end{array}$ & $91 \%$ & unknown \\
\hline & & $\begin{array}{l}\text { (CVA10 Australia } 2007 \\
\text { MF678312) }\end{array}$ & $(86 \%)^{a}$ & & & & & \\
\hline \multirow[t]{2}{*}{ Echo3 (7) } & $\begin{array}{l}\text { MF422567- } \\
\text { MF422572 }\end{array}$ & $\begin{array}{l}\text { Echo3 Japan } 2010 \\
\text { AB647320 }\end{array}$ & $94 \%$ & $\begin{array}{l}\text { Echo33 Thailand } 2011 \\
\text { KU574620 }\end{array}$ & $83 \%$ & $\begin{array}{l}\text { Echo3 Thailand } 2010 \\
\text { KU574635 }\end{array}$ & $94 \%$ & $P 1-P 2, P 2-P 3$ \\
\hline & KT353723 & $\begin{array}{l}\text { Echo3 Thailand } 2010 \\
\text { KU574635 }\end{array}$ & $92 \%$ & $\begin{array}{l}\text { Echo3 Finland } 2006 \\
\text { AJ849942 }\end{array}$ & $82 \%$ & $\begin{array}{l}\text { EVB85 USA } 2007 \\
\text { AY843303 }\end{array}$ & $86 \%$ & unknown \\
\hline Echo6 (1) & MF422579 & $\begin{array}{l}\text { Echo6 China } 2009 \\
\text { KP266568 }\end{array}$ & $95 \%$ & $\begin{array}{l}\text { Echo25 Germany } 2010 \\
\text { KX139459 }\end{array}$ & $82 \%$ & $\begin{array}{l}\text { Echo25 Germany } 2010 \\
\text { KX139459 }\end{array}$ & $88 \%$ & P1-P2 \\
\hline \multirow[t]{4}{*}{ Echo9 (2) } & MF422580 & $\begin{array}{l}\text { Echo } 9 \text { Finland } 2002 \\
\text { AF524867 }\end{array}$ & $92 \%$ & $\begin{array}{l}\text { Echo6 TW } 2008 \\
\text { KT353724 }\end{array}$ & $88 \%$ & $\begin{array}{l}\text { Echo6 TW } 2008 \\
\text { KT353724 }\end{array}$ & $89 \%$ & P1-P2 \\
\hline & MF422581 & $\begin{array}{l}\text { Echo9 USA } 2016 \\
\text { KX681481 }\end{array}$ & $92 \%$ & $\begin{array}{l}\text { Echo } 9 \text { USA } 2016 \\
\text { KX681481 }\end{array}$ & $88 \%$ & $\begin{array}{l}\text { Echo } 18 \text { Germany } 2010 \\
\text { KX139456 }\end{array}$ & $88 \%$ & unknown \\
\hline & & $\begin{array}{l}\text { (Echo9 Finland } 2012 \\
\text { KC238669) }^{\mathrm{b}}\end{array}$ & $(92 \%)^{b}$ & $\begin{array}{l}\text { (Echo } 9 \text { Finland } 2012 \\
\text { KC238669) }\end{array}$ & $(83 \%)^{b}$ & $\begin{array}{l}\text { (Echo } 9 \text { Finland } 2012 \\
\text { KC238669) }\end{array}$ & $(79 \%)^{b}$ & \\
\hline & & $\begin{array}{l}\text { (Echo } 30 \text { TW } 2006 \\
\text { EF066392) }\end{array}$ & $(69 \%)^{b}$ & $\begin{array}{l}\text { (Echo } 30 \text { TW } 2006 \\
\text { EF066392) }\end{array}$ & $(83 \%)^{b}$ & $\begin{array}{l}\text { (Echo } 30 \text { TW } 2006 \\
\text { EF066392) }\end{array}$ & $(86 \%)^{b}$ & \\
\hline \multirow[t]{2}{*}{ HPeV1 (1) } & KT726985 & $\begin{array}{l}\text { HPeV } 1 \text { Netherlands } 2007 \\
\text { GQ183034 }\end{array}$ & $88 \%$ & $\begin{array}{l}\text { HPeV1 Netherlands } 1993 \\
\text { GQ183022 }\end{array}$ & $85 \%$ & $\begin{array}{l}\text { HPeV } 1 \text { China } 2009 \\
\text { JX441355 }\end{array}$ & $86 \%$ & unknown \\
\hline & & $\begin{array}{l}\text { (HPeV } 1 \text { Australia } 2010 \\
\text { MG712784) }\end{array}$ & $(87 \%)^{a}$ & & & & & \\
\hline
\end{tabular}

${ }^{\mathrm{a} B l a s t}$ result of VP1 gene; ${ }^{\mathrm{b}}$ Strain selected by RDP 4.0 program

Overall, we successfully integrated VP1-CODEHOP and NGS techniques to improve enterovirus surveillance.

Recombination plays a crucial role in viral evolution and adaptation by repairing deleterious mutations in genomes, thus rescuing viral genes from low-fitness parents. Two viruses can exchange genetic material only in the case of co-infection of the same host cell. Two models of recombination have been proposed for enteroviruses: the template-switch model and the breaking-joining model $[11,23,24]$. In this study, we obtained 59 complete genome sequences for molecular epidemiological study. Among them, 23 genome variants were detected, and recombination events of nine genome variants were identified (1 CV-A10 strain, 6 Echo3 strains, 1 Echo6 strain, and 1 Echo9 strain).

Due to a lack of reference genomes, the recombination events of the remaining 14 genome variants could not be confirmed. Enteroviruses are RNA viruses and have high mutation rates and frequent recombination $[23,25,29]$. Therefore, it is desirable to generate more genome sequence data to understand the evolution of enteroviruses.

Many studies have revealed that recombination is a frequent phenomenon among enteroviruses. Interestingly, recombination events have been observed more frequently among members of the same species and have been detected mostly in strains from species B [23]. In our study, we also detected more gene recombination in species $\mathrm{B}$ viruses (Echo3, Echo6, and Echo9).

In our study, we detected $10 \mathrm{CV}$-A2 genome variants, which phylogenetically clustered together; but their recombination events could not be identified. Currently, there are about $14 \mathrm{CV}-\mathrm{A} 2$ genome sequences in the public domain, with only one strain collected before 2008. Therefore, it is hard to elucidate the evolution of the CV-A2 strains isolated in our study. Moreover, four CV-A2 viruses were isolated from an AFP patient in India from 2007 to 2009 [35] and variant CV-A2 caused four complicated cases in Hong Kong in 2012 [43]. The CV-A2 cases detected in our study resulted in only mild infections, but 


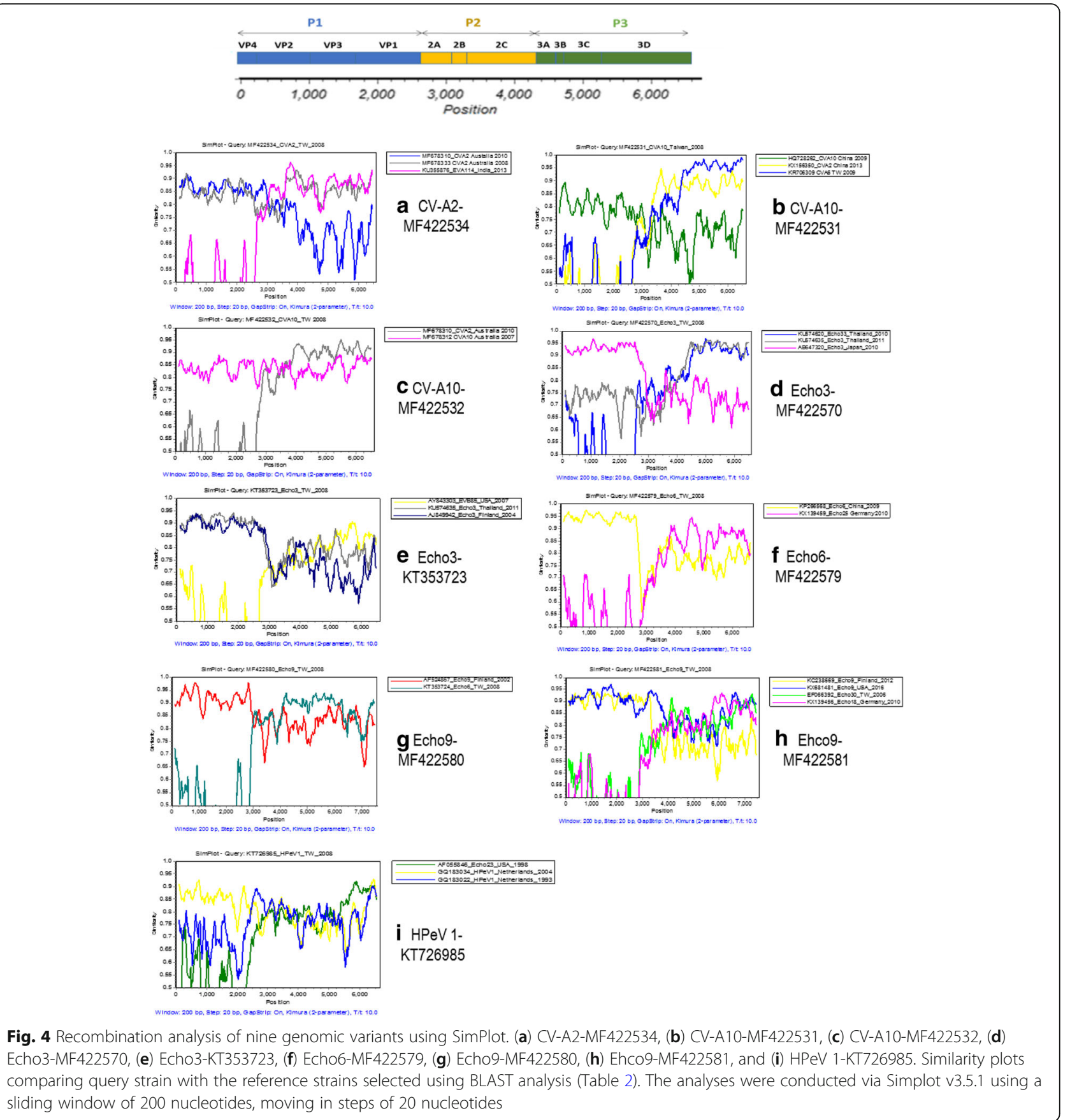

CV-A2 viruses have the potential to cause severe infections and need to be monitored intensively.

In this study, we found a genome variant of $\mathrm{CV}-\mathrm{A} 10$ (MF422531) that might be a triple recombinant of CVA10, CV-A2, and CV-A6, with the breakpoints occurring in $\mathrm{P} 1 / \mathrm{P} 2$ and $\mathrm{P} 2 / \mathrm{P} 3$ junctions. The recombination event of the other CV-A10 variant (MF422532) could not be identified. In a previous study, $\mathrm{Hu}$ et al. found that CVA10 isolated in China in 2009 is a recombinant between CV-A10 and EV-A, but the source of its P2 gene could not be confirmed [16]. Currently, about $65 \mathrm{CV}$ A10 genome sequences are in the public domain, only one of which was collected before 2008. Therefore, it is desirable to sequence more $\mathrm{CV}$-A10 strains isolated before 2008 .

EV-B is the most abundant species of enterovirus (63 serotypes), and intra species recombination of EV-B enterovirus has occurred frequently in the last decade [23, 44]. In our study, we also found that 3 of 6 serotypes (50\%) of EV-B enteroviruses were detected with genome 
recombination, which is higher than that of EV-A (2/7) (Table 3$)$. The only Echo6 variant is likely a recombinant of Echo6 and Echo25 and it causes mild infection (case 35, Additional file 2). Interestingly, the Echo6 genomic variants are not phylogenetically close to the other two Echo6 cases, which developed severe neurological complications (cases 48 and 49, Additional file 2). It is well documented that Echo6 causes seasonal epidemics of aseptic meningitis [2]. There are about 21 Echo6 genome sequences in the public domain, and only three of them were collected before 2008. Therefore, it is necessary to actively monitor the Echo6 virus and sequence more Echo6 strains isolated before 2008.

In our study, an Echo9 variant (MF422581) was found to be a recombinant of Echo9 and Echo30 using the RDP program; but the recombination event could not be confirmed using BLAST and Simplot analysis. In general, RDP is an automatic program for screening recombination events, and BLAST and Simplot analyses are more reliable. Therefore, the recombination events detected using RDP need to be verified using BLAST and Simplot analyses. There are about 12 Echo9 genome sequences in the public domain, and it is necessary to sequence more Echo9 strains. One Echo9 (MF422580) genomic variant causes mild infection and the other Echo9 (MF22581) causes aseptic meningitis, which is consistent with other studies that found Echo9 strains frequently cause aseptic meningitis in Asia [17, 45].

Human parechovirus ( $\mathrm{HPeV}$ ) were first detected in 1956 and classified into 19 serotypes. HPeV primarily causes sepsis and central nervous system diseases in infants, and still has other unproven clinical manifestations [36]. HPeV is not yet included for serotyping using IFA in the Taiwan Virology Reference Laboratory Network, but they have been detected using molecular techniques in Taiwan since 2007 [18]. It has been documented that $\mathrm{HPeV}$ culture is still limited due to the low induction of CPE, and more sensitive VP1 primers are required for different $\mathrm{HPeV}$ genotypes $[4,42]$. In our study, the HPeV strain could not be detected using the CODEHOP method but could be identified using NGS technology without the requirement of designing specific primers. Interestingly, the HPeV1 strain (KT726985) in our study was phylogenetically classified into Clade A - in contrast to other Taiwan HPeV1 strains, which belong to the Clade B circulating in 2007$2012[12,18]$. This HPeV 1 (KT726985) strain is a genomic variant but its source could not be identified due to limited genome sequence and high variability.

Life-threatening outbreaks of EV-D68 emerged in 2014 in North United States [9] and gradually spread to multiple countries [7, 19, 27]. EV-D68 infections in children usually manifest with respiratory symptoms and may cause neurological complications. It is necessary to strengthen EV-D68 detection globally [39]. Virus isolation from cell culture has been used for many years for the detection of enteroviruses. RT-PCR is generally more sensitive and more rapid than virus isolation $[5,6]$, but not all laboratories are equipped to test for enteroviruses. Moreover, many available laboratory methods for the detection of EVs cannot distinguish between enteroviruses and rhinoviruses, and provide no information on serotypes [21]. Some of the severe rhinovirus infections previously described during the 2009-2014 period were actually EVD68 [28]. In the current study, we detected one EV-D68 strain using the CODEHOP method. Recently, the Taiwan Centers for Disease Control further detected EV-D68 from acute flaccid paralysis patients using the CODEHOP method. Therefore, the CODEHOP method could be widely used for detection of EV-D68.

Previous studies found that enterovirus co-infection may cause more severe symptoms $[8,13]$. Enterovirus co-infections are seldom detected using the traditional IFA and RT-PCR methods, because these methods are more likely to detect the predominant strain in a clinical specimen. We detected eight co-infection events using the NGS method in this study. Therefore, VP1CODEHOP and NGS could be used together for genomic analysis of serologically untypable enteroviruses. Both of them should be integrated into enterovirus surveillance to help clinical management and identification of novel enteroviruses.

\section{Conclusion}

Cost is a critical issue for the widespread use of NGS. In the pilot study, we first concentrated enterovirus with ultracentrifugation. Then we generated 3-10 million reads for each concentrated enterovirus sample and the NGS sample 1-10 genome sequence were obtained through de novo assembly (Additional file 2). The distribution of read depth for each enterovirus genome was 20,201 to 123,641 reads; and the average read depth was about 80,476 , which indicates that compression of sequencing reads is a possible way to reduce the cost of NGS sequencing (Additional file 5). In the NGS study two, we generated $0.3-1.5$ million reads for each concentrated enterovirus sample to reduce sequencing cost. Based on our results, we believe that 0.5 million reads of raw data would suffice for NGS sequencing of each concentrated enterovirus sample; this could further reduce the cost of sequencing. In the pilot study, we generated 3-10 megabyte reads through a contract research organization; this cost about US $\$ 500$ per sample. In the NGS study two, we collaborated with the J. Craig Venter Institute and generated 0.3-1.5 megabyte reads for each sample. It is hard to precisely calculate the cost of library construction and genome sequencing in the NGS study two. 
In conclusion, we successfully integrated VP1-CODEHOP and NGS techniques to conduct genomic analysis of serologically untypable enteroviruses, which could not only improve enterovirus surveillance but also provide genome sequences for evolution research.

\section{Additional files}

Additional file 1: Analysis of enterovirus genomes sequenced using NGS in a pilot study. (DOCX $21 \mathrm{~kb}$ )

Additional file 2: Characteristics of enterovirus patients characterized using NGS in Taiwan, 2008. (DOCX 23 kb)

Additional file 3: Flowchart of the next-generation sequencing (NGS) method. (PDF $85 \mathrm{~kb}$ )

Additional file 4: Recombination analysis of MF422581_E9_TW_2008 using the RDP 4.0 program. The analyses were conducted via RDP 4.0 using the manual Bootscan method. Windows200 nt, step 20 nt. (PDF 194 $\mathrm{kb})$

Additional file 5: Sequencing coverage of each NGS sample. (XLSX 23 $\mathrm{kb})$

Additional file 6: Contributions of all enterovirus reference strain serotype. (XLSX $13 \mathrm{~kb})$

\section{Acknowledgments}

The authors thank the staff of the Linkou Chang Gung Memorial Hospital's Virology Lab for collecting virus isolates.

\section{Authors' contributions}

MSL designed the experiments, wrote the manuscript, and analyzed the data. YSC performed the experiments, analyzed the data, and wrote the manuscript. STL and WYC prepared reagents and materials. KCT and YCH contributed samples and clinical analysis. YCL, YT, and SRD analyzed the data. All authors approved the final manuscript as submitted and agree to be accountable for all aspects of the work.

\section{Funding}

This study was supported by funding from the National Health Research Institutes of Taiwan (06A1-IVPP12-014) and the National Flagship Project (MOST 106-3114-Y404-002).

\section{Availability of data and materials}

All data generated or analyzed during this study are included in this published article [and its supplementary information files].

\section{Ethics approval and consent to participate}

This study was approved by the Institutional Review Board of Chang Gung Memorial Hospital following the Helsinki Declaration (IRB: 104-9203B). Under Taiwan's Communicable Disease Control Act, informed consent is not required to collect clinical specimens from patients with suspected notifiable communicable diseases.

\section{Consent for publication}

Not applicable.

\section{Competing interests}

The authors declare no competing interests.

\section{Author details}

'Institute of Infectious Disease and Vaccinology, National Health Research Institutes, Zhunan, Miaoli County, Taiwan. ${ }^{2}$ Department of Life Sciences, National Central University, Taoyuan, Taiwan. ${ }^{3}$ Department of Medical Biotechnology and Laboratory Science, College of Medicine, Chang Gung University, Guishan, Taoyuan County, Taiwan. ${ }^{4}$ Department of Pediatrics, Linkou Chang Gung Memorial Hospital, Guishan, Taoyuan County, Taiwan. ${ }^{5}$ Division of Infectious Diseases, Department of Medicine, Vanderbilt University Medical Center, Nashville, Tennessee, USA. ${ }^{6}$ Institute of Population
Health Sciences, National Health Research Institutes, Zhunan, Miaoli County, Taiwan. ${ }^{7}$ National Health Research Institutes, R1-7F, 35 Keyan Road, Zhunan, Miaoli County 350, Taiwan.

Received: 15 March 2019 Accepted: 11 June 2019

Published online: 03 July 2019

\section{References}

1. Guidelines for enterovirus surveillance in support of the polio eradication initiative.: World Health Organization; 2015.

2. Bailly JL, Mirand A, Henquell C, Archimbaud C, Chambon M, Regagnon C, Charbonne F, Peigue-Lafeuille $H$. Repeated genomic transfers from echovirus 30 to echovirus 6 lineages indicate co-divergence between cocirculating populations of the two human enterovirus serotypes. Infect Genet Evol. 2011;11(2):276-89.

3. Barzon L, Lavezzo E, Militello V, Toppo S, Palu G. Applications of nextgeneration sequencing technologies to diagnostic virology. Int J Mol Sci. 2011;12(11):7861-84

4. Benschop K, Thomas X, Serpenti C, Molenkamp R, Wolthers K. High prevalence of human Parechovirus ( $\mathrm{HPeV}$ ) genotypes in the Amsterdam region and identification of specific $\mathrm{HPeV}$ variants by direct genotyping of stool samples. J Clin Microbiol. 2008:46(12):3965-70.

5. Chiang PS, Huang ML, Luo ST, Lin TY, Tsao KC, Lee MS. Comparing molecular methods for early detection and serotyping of enteroviruses in throat swabs of pediatric patients. PLoS One. 2012;7(10):e48269.

6. Chung WY, Chiang PS, Luo ST, Lin TY, Tsao KC, Lee MS. A molecular approach applied to enteroviruses surveillance in northern Taiwan, 20082012. PLoS One. 2016;11(12):e0167532.

7. Esposito S, Bosis S, Niesters H, Principi N. Enterovirus D68 infection. Viruses. 2015;7(11):6043-50.

8. Foster CB, Coelho R, Brown PM, Wadhwa A, Dossul A, Gonzalez BE, Cardenas S, Sabella C, Kohn D, Vogel S, Yen-Lieberman B, Piedimonte G. A comparison of hospitalized children with enterovirus D68 to those with rhinovirus. Pediatr Pulmonol. 2017;52(6):827-32.

9. Foster CB, Friedman N, Carl J, Piedimonte G. Enterovirus D68: a clinically important respiratory enterovirus. Cleve Clin J Med. 2015;82(1):26-31.

10. Geoghegan JL, Tan le V, Kuhnert D, Halpin RA, Lin X, Simenauer A, Akopov A, Das SR, Stockwell TB, Shrivastava S, Ngoc NM, Uyen le TT, Tuyen NT, Thanh TT, Hang VT, Qui PT, Hung NT, Khanh TH, Thinh le Q, Nhan le NT, Van HM, Viet do C, Tuan HM, Viet HL, Hien TT, Chau NV, Thwaites G, Grenfell BT, Stadler T, Wentworth DE, Holmes EC, Van Doorn HR. Phylodynamics of Enterovirus A71-associated hand, foot, and mouth disease in Viet Nam. J Virol. 2015;89(17):8871-9.

11. Gmyl AP, Korshenko SA, Belousov EV, Khitrina EV, Agol VI. Nonreplicative homologous RNA recombination: promiscuous joining of RNA pieces? RNA. 2003;9(10):1221-31.

12. Gong YN, Chen GW, Yang SL, Lee CJ, Shih SR, Tsao KC. A next-generation sequencing data analysis pipeline for detecting unknown pathogens from mixed clinical samples and revealing their genetic diversity. PLoS One. 2016; 11(3):e0151495

13. Han JF, Zhang Y, Hou PQ, Zhu SY, Wu XY, Zhao H, Yu M, Qin CF. Human enterovirus co-infection in severe HFMD patients in China. Clin Virol. 2014;61(4):621-2.

14. Harvala H, Broberg E, Benschop K, Berginc N, Ladhani S, Susi P, Christiansen C, McKenna J, Allen D, Makiello P, McAllister G, Carmen M, Zakikhany K, Dyrdak R, Nielsen X, Madsen T, Paul J, Moore C, von Eije K, Piralla A, Carlier M, Vanoverschelde L, Poelman R, Anton A, Lopez-Labrador FX, Pellegrinell L, Keeren K, Maier M, Cassidy H, Derdas S, Savolainen-Kopra C, Diedrich S, Nordbo S, Buesa J, Bailly JL, Baldanti F, MacAdam A, Mirand A, Dudman S, Schuffenecker I, Kadambari S, Neyts J, Griffiths MJ, Richter J, Margaretto C, Govind S, Morley U, Adams O, Krokstad S, Dean J, Pons-Salort M, Prochazka B, Cabrerizo M, Majumdar M, Nebbia G, Wiewel M, Cottrell S, Coyle P, Martin J, Moore C, Midgley S, Horby P, Wolthers K, Simmonds P, Niesters H, Fischer TK. Recommendations for enterovirus diagnostics and characterisation within and beyond Europe. J Clin Virol. 2018;101:11-7.

15. Hoper D, Hoffmann B, Beer M. A comprehensive deep sequencing strategy for full-length genomes of influenza a. PLoS One. 2011;6(4):e19075.

16. Hu YF, Yang F, Du J, Dong J, Zhang T, Wu ZQ, Xue Y, Jin Q. Complete genome analysis of coxsackievirus $A 2, A 4, A 5$, and $A 10$ strains isolated from hand, foot, and mouth disease patients in China revealing frequent recombination of human enterovirus a. J Clin Microbiol. 2011;49(7):2426-34. 
17. Huang Y, Zhou Y, Lu H, Yang H, Feng Q, Dai Y, Chen L, Yu S, Yao X, Zhang $H$, Jiang M, Wang $Y$, Han N, Hu G, He Y. Characterization of severe hand, foot, and mouth disease in Shenzhen, China, 2009-2013. J Med Virol. 2015; 87(9):1471-9.

18. Huang YP, Hsieh JY, Wu HS, Yang JY. Molecular and epidemiological study of human parechovirus infections in Taiwan, 2007-2012. J Microbiol Immunol Infect. 2016;49(3):321-8.

19. Huang YP, Lin TL, Lin TH, Wu HS. Molecular and epidemiological study of enterovirus D68 in Taiwan. J Microbiol Immunol Infect. 2017;50(4):411-7.

20. Ibrahim W, Ouerdani I, Pillet S, Aouni M, Pozzetto B, Harrath R. Direct typing of human enteroviruses from wastewater samples. J Virol Methods. 2014;207:215-9.

21. Jaramillo-Gutierrez G, Benschop KS, Claas EC, de Jong AS, van Loon AM, Pas SD, Pontesilli O, Rossen JW, Swanink CM, Thijsen S, van der Zanden AG, van der Avoort HG, Koopmans MP, Meijer A. September through October 2010 multi-Centre study in the Netherlands examining laboratory ability to detect enterovirus 68, an emerging respiratory pathogen. J Virol Methods. 2013; 190(1-2):53-62.

22. Kuroda M, Katano H, Nakajima N, Tobiume M, Ainai A, Sekizuka T, Hasegawa H, Tashiro M, Sasaki Y, Arakawa Y, Hata S, Watanabe M, Sata T. Characterization of quasispecies of pandemic 2009 influenza a virus (a/ H1N1/2009) by de novo sequencing using a next-generation DNA sequencer. PLoS One. 2010;5(4):e10256.

23. Kyriakopoulou Z, Pliaka V, Amoutzias GD, Markoulatos P. Recombination among human non-polio enteroviruses: implications for epidemiology and evolution. Virus Genes. 2015;50(2):177-88.

24. Lowry K, Woodman A, Cook J, Evans DJ. Recombination in enteroviruses is a biphasic replicative process involving the generation of greater-than genome length 'imprecise' intermediates. PLoS Pathog. 2014;10(6):e1004191.

25. Lukashev AN, Shumilina EY, Belalov IS, Ivanova OE, Eremeeva TP, Reznik VI, Trotsenko OE, Drexler JF, Drosten C. Recombination strategies and evolutionary dynamics of the human enterovirus a global gene pool. J Gen Virol. 2014;95(Pt 4:868-73.

26. Martin DP, Murrell B, Golden M, Khoosal A, Muhire B. RDP4: detection and analysis of recombination patterns in virus genomes. Virus Evol. 2015;1 (1):vev003.

27. Martin G, Li R, Cook VE, Carwana M, Tilley P, Sauve L, Tang P, Kapur A, Yang $\mathrm{CL}$. Respiratory presentation of pediatric patients in the 2014 Enterovirus D68 outbreak. Can Respir J. 2016;2016:8302179.

28. McAllister SC, Schleiss MR, Arbefeville S, Steiner ME, Hanson RS, Pollock C Ferrieri P. Epidemic 2014 enterovirus D68 cross-reacts with human rhinovirus on a respiratory molecular diagnostic platform. PLoS One. 2015;10(3):e0118529.

29. McWilliam Leitch EC, Cabrerizo M, Cardosa J, Harvala H, Ivanova OE, Kroes AC, Lukashev A, Muir P, Odoom J, Roivainen M, Susi P, Trallero G, Evans DJ, Simmonds P. Evolutionary dynamics and temporal/geographical correlates of recombination in the human enterovirus echovirus types 9,11 , and $30 . J$ Virol. 2010;84(18):9292-300.

30. Medina DJ, Tsai CH, Hsiung GD, Cheng YC. Comparison of mitochondrial morphology, mitochondrial DNA content, and cell viability in cultured cells treated with three anti-human immunodeficiency virus dideoxynucleosides. Antimicrob Agents Chemother. 1994;38(8):1824-8.

31. Nix WA, Oberste MS, Pallansch MA. Sensitive, seminested PCR amplification of VP1 sequences for direct identification of all enterovirus serotypes from original clinical specimens. J Clin Microbiol. 2006;44(8):2698-704.

32. Ortner B, Huang CW, Schmid D, Mutz I, Wewalka G, Allerberger F, Yang JY, Huemer HP. Epidemiology of enterovirus types causing neurological disease in Austria 1999-2007: detection of clusters of echovirus 30 and enterovirus 71 and analysis of prevalent genotypes. J Med Virol. 2009;81(2):317-24.

33. Palmenberg AC, Spiro D, Kuzmickas R, Wang S, Djikeng A, Rathe JA, Fraser-Liggett CM, Liggett SB. Sequencing and analyses of all known human rhinovirus genomes reveal structure and evolution. Science. 2009;324(5923):55-9.

34. Pham NTK, Thongprachum A, Trinh QD, Okitsu S, Komine-Aizawa S, Shimizu $\mathrm{H}$, Hayakawa S, Ushijima H. Detection and genetic characterization of enterovirus strains circulating among children with acute gastroenteritis in Japan during 2014-2016. Infect Genet Evol. 2018;61:16-9.

35. Rao CD, Yergolkar P, Shankarappa KS. Antigenic diversity of enteroviruses associated with nonpolio acute flaccid paralysis, India, 2007-2009. Emerg Infect Dis. 2012;18(11):1833-40.

36. Shah G, Robinson JL. The particulars on parechovirus. Can J Infect Dis Med Microbiol. 2014;25(4):186-8.
37. Shingler KL, Organtini LJ, Hafenstein S. Enterovirus 71 virus propagation and purification. Bio Protoc. 2014;4(9).

38. Solomon T, Lewthwaite P, Perera D, Cardosa MJ, McMinn P, Ooi MH. Virology, epidemiology, pathogenesis, and control of enterovirus 71. Lancet Infect Dis. 2010;10(11):778-90.

39. Tan Y, Hassan F, Schuster JE, Simenauer A, Selvarangan R, Halpin RA, Lin X, Fedorova N, Stockwell TB, Tsan-Yuk Lam T, Chappell JD, Hartert TV, Holmes EC, Das SR. Molecular evolution and intra-clade recombination of Enterovirus D68 during the 2014 outbreak in the United States. J Virol. 2015

40. Tauro BJ, Greening DW, Mathias RA, Ji H, Mathivanan S, Scott AM, Simpson RJ. Comparison of ultracentrifugation, density gradient separation, and immunoaffinity capture methods for isolating human colon cancer cell line LIM1863-derived exosomes. Methods. 2012;56(2):293-304.

41. Tsao KC, Huang CG, Huang YL, Chen FC, Huang PN, Huang YC, Lin TY, Shih SR, Chang SC. Epidemiologic features and virus isolation of enteroviruses in northern Taiwan during 2000-2008. J Virol Methods. 2010;165(2):330-2.

42. van der Sanden $\mathrm{S}$, de Bruin E, Vennema H, Swanink C, Koopmans M, van der Avoort H. Prevalence of human parechovirus in the Netherlands in 2000 to 2007. J Clin Microbiol. 2008;46(9):2884-9.

43. Yip CC, Lau SK, Woo PC, Wong SS, Tsang TH, Lo JY, Lam WK, Tsang CC, Chan $\mathrm{KH}$, Yuen KY. Recombinant coxsackievirus A2 and deaths of children, Hong Kong, 2012. Emerg Infect Dis. 2013;19(8):1285-8.

44. Zell et al. K.e.a., 2012; Adams et al., 2013, 2014, 2015; 2016; ICTV Master Species List 2016. 2017. Picornavirus website http://www.picornaviridae.com. . < http://www.picornaviridae.com. >. Accessed.

45. Zhu Y, Zhou X, Liu J, Xia L, Pan Y, Chen J, Luo N, Yin J, Ma S. Molecular identification of human enteroviruses associated with aseptic meningitis in Yunnan province, Southwest China. Springerplus. 2016;5(1):1515.

\section{Publisher's Note}

Springer Nature remains neutral with regard to jurisdictional claims in published maps and institutional affiliations.

Ready to submit your research? Choose BMC and benefit from:

- fast, convenient online submission

- thorough peer review by experienced researchers in your field

- rapid publication on acceptance

- support for research data, including large and complex data types

- gold Open Access which fosters wider collaboration and increased citations

- maximum visibility for your research: over $100 \mathrm{M}$ website views per year

At BMC, research is always in progress.

Learn more biomedcentral.com/submissions 